\title{
Hablar de los 90. Variaciones de una comunidad
}

\section{( Damián Lamanna Guiñazú}

Centro Cultural de la Memoria Haroldo Conti - Universidad Nacional de Tres de Febrero, Argentina

\begin{abstract}
Resumen
El artículo analiza producciones actuales que abordan la generación argentina de poetas de los 90, algunas de ellas elaboradas por los propios integrantes de dicho grupo poético: el último número de la revista La Trompa de Falopo, publicado en 2020 tras la muerte de Ricardo "Circo" Cerqueiro; el documental de Mario Varela La vida que te agenciaste (2018); y otros dos textos de los últimos años: Hierba sobre el mundo castigado, del Colectivo poético involuntario (2017) y La poesía en estado de pregunta, entrevistas realizadas por el poeta Osvaldo Aguirre (2014). Algunas preguntas que organizan el recorrido del artículo son: ¿existe acaso algún deslizamiento entre la idea de generación y la idea de comunidad?, ¿hay una deuda común que pueda condensarse como una estética o una política?, ¿por qué el afán de estos poetas de representarse a sí mismos una vez más? Por último, ¿por qué ese pasado insiste con volver reconvertido?, ¿una nueva revista reemplaza a un cuerpo para que no quede nada por saldar?
\end{abstract}

PALABRAS CLAVE: poesía argentina de los 9o, revistas, comunidad, generación

\section{Talk about the gos. Variations of a community}

\begin{abstract}
The article analyzes current productions that study the gos Argentine generation of poets, some of them produced by the members of the mentioned poetic group: the last publication of the magazine La Trompa de Falopo, published in 2020 after the death of Ricardo "Circo "Cerqueiro; Mario Varela's documentary La vida que te agencies (2018); and two other texts from recent years: Hierba sobre el mundo castigado by the Colectivo poético involuntario (2017) and La poesía en estado de pregunta, interviews done by the poet Osvaldo Aguirre (2014). Some questions that could organize this
\end{abstract}


text are: Is there perhaps a slippage between the idea of generation and the idea of community? Is there a common debt that can be condensed as an aesthetic or a policy? Why the persistence ofthese poets to represent themselves once again? Finally, why does that past insist on returning reconverted? Does a new magazine replace a body so that there is nothing left to solve?

KEYWORDS: 9os Argentine poetry, magazines, community, generation

\section{Falar dos anos 90. Variações de uma comunidade}

\section{Resumo}

O artigo analisa as produções atuais que abordam a geração de poetas argentinos dos anos 90 , algumas delas produzidas pelos próprios integrantes desse grupo poético: o último número da revista La Trompa de Falopo, publicada em 2020 após a morte de Ricardo "Circo" Cerqueiro; o documentário La vida que te agenciaste, de Mario Varela (2018); e dois outros textos dos últimos anos: Hierba sobre el mundo castigado, do Colectivo Poético Involuntario(2017) e La poesía en estado de pregunta, entrevistas realizadas pelo poeta Osvaldo Aguirre (2014). Algumas perguntas que organizam o texto são: será que existe algum deslizamento entre a ideia de geração e a ideia de comunidade? Existe uma dívida comum que pode ser condensada como uma estética ou uma política? Por que a ânsia desses poetas em se representarem mais uma vez? Finalmente, por que esse passado insiste em voltar reconvertido? Será que uma nova revista substitui um corpo para que não haja mais nada a resolver?

PALAVRAS-CHAVE: poesia argentina dos anos 9o, revistas, comunidade, geração

Casi tres décadas después de su último número en 2020, apareció uno nuevo de $\mathrm{La}$ Trompa de Falopo, una de las revistas que nucleara a los llamados poetas o generación de los noventa. La motivación fue la muerte de Ricardo "Circo" Cerqueiro, integrante de este grupo de poetas y artistas, a esta altura disgregado. Para los lectores y espectadores, la imagen de Cerqueiro está fresca: es una de las voces que recupera el mito en La vida que te agenciaste (2018), documental de Mario Varela acerca de la mítica 18 Whiskys. En Communitas (2007), Roberto Esposito piensa la idea de comunidad a partir de la falta. Para el italiano, una comunidad puede ser en tanto haya una deuda, una pérdida común a todos sus integrantes. En las siguientes páginas propongo un análisis que parta de estas nuevas producciones y de otros dos textos de los últimos años: Hierba sobre el mundo castigado del Colectivo poético involuntario (2017) y La poesía en estado de pregunta, entrevistas realizadas por el poeta Osvaldo Aguirre (2014). Algunas preguntas que pueden organizar este recorrido: ¿existe acaso algún deslizamiento entre la idea de generación y la idea de comunidad?, ¿hay una deuda común que pueda condensarse como una estética o una política?, ¿por qué el afán de estos poetas de representarse a sí mismos una vez más? Por último, ¿por qué ese pasado insiste con volver reconvertido?, ¿una nueva revista reemplaza a un cuerpo para que no quede nada por saldar?

1. Casi tres décadas después de su último número, fechado en marzo de 1992, en octubre de 2020 apareció el séptimo número de la revista La Trompa de Falopo, una de las publicaciones que nucleó a algunos de los llamados poetas de la generación del noventa. A diferencia de los números anteriores, esta edición no es un cuadernillo de papel tipeado a máquina de escribir e impreso en blanco y negro, sino un archivo en 
formato PDF a color. ${ }^{1}$ Conserva, sin embargo, elementos en común: por un lado, se sostiene aún aquella idea de circulación no mercantil pero de una forma actualizada, que va de los kioscos a la nube digital, potenciando siempre una circulación mediada por lo vincular, por el contacto entre poetas y lectores, que quizás sean, en el plano de la poesía, la misma cosa. Al final de los créditos del número 7 se lee:

Esta edición no estará en los kioscos ni alojada en nubes de almacenamiento ni ninguna de esas mierdas tecnológicas. Se comparte de mano en mano, como las buenas tradiciones orales (2020: 2)

Por otro lado, se hace hincapié en la provocación (aunque no queda claro hacia quién) y el humor, con la capacidad que este grupo tiene de reírse incluso de la muerte. Al respecto, el dossier de poemas de esta edición "no apta para caretas", un clásico de la revista en los viejos tiempos, se titula "Colección nuestros muertos $n^{\circ}$ 1" (2020: 51).

Sin embargo, a diferencia de la primera época (1989-1993), el séptimo número de La Trompa de Falopo no se insertará (voluntariamente) dentro de un sistema de publicaciones -como las revistas 18 Whiskys, La mineta o el Diario de Poesía (siquiera por oposición)- que busque visibilizar la obra de algún poeta joven o de forjar una tradición alternativa, objetivos centrales en el pasado. Estamos ahora frente a un grupo de poetas que han superado los cincuenta años y se reúne alrededor de su primer muerto para velarlo y homenajearlo a través de poemas, cartas y anécdotas: Ricardo "Circo" Cerqueiro, fallecido en 2018, integrante de la revista La Trompa de Falopo y también participante de 18 Whiskys, del grupo de amigos y de la generación. Una comunidad que se congrega y vuelve a ser a partir del poeta que ya no está.

Aun cuando esta edición de La Trompa de Falopo se haya despegado de su tiempo y ya no pertenezca a un sistema de publicaciones que se retroalimentan entre sí de forma programática, es posible situarla dentro de un nuevo sistema de obras (libros y películas) que buscarán narrar o construir una idea de generación o comunidad que persiste. Nos interesa reflexionar sobre esta inflexión temporal relativamente nueva: la de una generación poética de alta exposición y nutrida autorreflexión (hay varias antologías, tesis, artículos, y otras formas de difusión sostenidas por varios de sus miembros) que, muchos años después de su emergencia, continúa produciendo algún tipo de manifestación colectiva. Una manifestación, generalmente reservada a los comienzos y casi siempre abandonada en el curso de los años, que ahora se expresa en el ejemplo antedicho del número digital de La Trompa de Falopo o en otras formas artísticas. En ese grupo podemos hallar las entrevistas de La poesía en estado de pregunta, de Osvaldo Aguirre (2014); el poema coral Hierba sobre el mundo castigado del "Colectivo poético involuntario" (2017), compuesto por las poetas Teresa Arijón y María Mascheroni; y el documental de Mario Varela, La vida que te agenciaste (2018). Formas que abordaremos en las siguientes páginas, luego de reflexionar sobre el vínculo de la poesía con el presente, la memoria colectiva y la comunidad que inspiran dos textos de Giorgio Agamben y de Gaston Bachelard, para enmarcar la experiencia

1 El número puede consultarse en la página de internet www.lasraras.com.ar, que responde al proyecto de investigación radicado en la Maestría de Escritura Creativa de la Universidad Nacional de Tres de Febrero (UNTREF) "Las raras. Revistas de poesía de los 90”, dirigido por Jorge Monteleone e integrado por Lucía Dorín, Lucrecia Frasetto, Laura Junowicz y el autor de este artículo, Damián Lamanna Guiñazú. Como señala la presentación, “Este proyecto se propone recuperar la experiencia de una serie de revistas literarias argentinas de poesía de la década del 90 (publicadas entre 1998 y 2001) que se instalaron como alternativa o discurso periférico frente a la revista Diario de poesía, el gran órgano de consagración poética de las tres últimas décadas, particularmente en el ámbito de la ciudad de Buenos Aires". La plataforma incluye colecciones completas de revistas del período digitalizadas (entre ellas, La Trompa de Falopo), los primeros libros digitalizados de poetas de la época junto con sus testimonios, numerosos textos críticos, materiales audiovisuales (como el film que estudiamos aquí, La vida que te agenciaste), testimonios escritos y orales de los protagonistas, documentos diversos y videopoemas. Este artículo también surge de ese proyecto de investigación radicado en la UNTREF. 
de los poetas de los noventa en este regreso temporal que aquí estudiamos (y que vincularemos luego con la idea de comunidad a partir de la falta, que postuló Roberto Esposito).

2. En dos de los microensayos que integran Idea de la prosa, "Idea de lo inmemorial" e "Idea del comunismo", Agamben evoca un tiempo-espacio anterior a aquello que los seres humanos podemos soñar o recordar. Un vacío que excede y a la vez posibilita esos recuerdos y sueños que se despliegan (aunque luego se desvanecen) con potencia de verdad (2015: 59). Opacidades que en el mismo instante en que construyen un sentido trascendental, se vuelven inasibles y desaparecen para que los ojos se abran. En otras palabras, existiría una huella prelingüística que subyace a la representación de cualquier experiencia tangible y se concibe como ese inolvidable olvido que una y otra vez regresa para hacer temblar el presente. Los seres humanos miran hacia su pasado, se sumergen en el plano onírico en tanto deseo de libertad, para construir un nuevo mundo posible, y levantan su cabeza hacia los dibujos "jamás soñados" que habitan las estrellas y no pueden descifrar (2015: 72).

Allí se desplegaría también la imposibilidad fundacional del poema, su reverso activo, su motor. El poema en tanto fenómeno que cintila, quizá por única vez (aunque leamos las mismas líneas muchas veces), dentro de la conciencia y deja una huella de sí que se proyecta hacia el futuro, para reaparecer en nuevas imágenes y formas. En este sentido es posible seguir la paradoja de Agamben: hay un recuerdo que vive porque desaparece; una memoria que es también una visión venida del futuro - de un deseo o una imaginación imposible- para construir en nosotros una idea de comunidad, una eclosión de las jerarquías. "El poeta es un vidente", dijo Rimbaud (2007 [1871]: 79): el rasgo visionario siempre implica una mirada prospectiva. El futuro irrepresentado condensa cada uno de los ecos olvidados, brilla detrás del lenguaje y, a la vez, lo define como tal. Vamos hacia un territorio que no sabemos si existe pero la trayectoria misma conduce, quizás, a su materialización.

Gaston Bachelard ya había pensado en esa dirección en el último libro que publicó en vida. En La llama de una vela, aparecido en 1961, el filósofo francés hace hincapié en la idea de ensoñación (rêverie) para pensar una zona intermedia, a mitad de camino entre el sueño y el recuerdo. Parte de una imagen fascinante, la evocación de un tiempo trascendental a partir de la contemplación de una llama. Dice:

La llama nos exige ver como si fuera la primera vez: tenemos miles de recuerdos, soñamos todo a la luz de la personalidad de una memoria de años, y sin embargo soñamos como todo el mundo (...) el soñador vive en un pasado que no es únicamente suyo sino el pasado de los primeros fuegos del mundo. (Bachelard, 2015: 8-9)

A través de la llama, de la contemplación de su fulgor que asciende al cielo como un acto de ensueño, los seres humanos se encuentran con un origen que les es común. Podemos pensar que cada vez que un ser humano mira el fuego, en el ritmo de las llamas no solo se figuran todos los fuegos del pasado sino también se prefiguran los del futuro. En este ritual, en la transparencia -constituida como símbolo de encuentro, reposo e hipnosis que tarde o temprano se extinguirá- se despliega una raíz de lo humano, un vínculo primario que daría lugar a una comunidad posible, aquella que para Agamben subsiste encriptada en las estrellas. Nos entregamos, entonces, a las imágenes que anidan en el fuego sin saber por qué, ofrendamos papeles arrugados a las llamas y vemos cómo, en ese límpido acto, la violencia -que discrimina, separa y destruye lo unitivo- se vacía, se vuelve inofensiva. Nadie dice yo alrededor del fuego, en el sentido de un yo solipsista, individualista. La conciencia se entrega al pasaje como si una verdad habitara allí, un rincón donde permanecer. El fuego proyecta a nuestras espaldas sombras humanas en una pared imaginaria. Las sombras protegen 
el fuego en lo más profundo de la memoria, que es colectiva. Ese es, para Bachelard, el contenido de una ensoñación poética.

Tanto para Bachelard como para Agamben, en el poema, en el regreso y desaparición del inolvidable olvido que lo determina, radicaría la posibilidad de encontrarse con los otros. Lo inmemorial que habita en el recuerdo y el sueño es, también, ese pasado arcaico, incluso sagrado, que se revela hacia el interior de la llama que evoca todas las llamas. Un pasado junto a los otros proyectado como ilusión de futuro. Es posible, coinciden ambos pensadores, construir esa comunidad que alguna vez existió en un tiempo inmemorial y ahora resplandece en la intimidad compartida del fuego o de las estrellas.

En este punto Roland Barthes nos ofrece un camino, una visión de comunidad o de grupo. Se pregunta en el seminario "Cómo vivir juntos", refiriéndose a pequeñas comunidades, entre las cuales bien podría estar la de los poetas: “¿Qué es lo que fascina en el pequeño grupo?". Y justamente lo que fascina es "el estado de autarquía (autarkeia: suficiencia, contento = plenitud). No es el vacío lo que atrae, es lo pleno, o, si se prefiere, la intuición del vacío vertiginoso de la plenitud del grupo" (2003: 82). Entre vacío y plenitud se reproduce la misma dialéctica. Lo desaparecido en el pasado resplandece en un fulgor único y efímero que ensancha el presente. Es posible acaso concentrar ese instante como una ofrenda para que el futuro exista. Experimentar la epifanía para poder perderla.

La última escena de La vida que te agenciaste lo deja entrever. Las revistas abandonadas en la orilla como una ofrenda al mar. O mejor dicho, la imagen de las revistas en descomposición que, una vez que el agua se las lleve, nos dejan con su pérdida. En la arena vacía -la ofrenda, los fantasmas, la muerte- anida una nueva idea de comunidad.

3. La vida que te agenciaste, "segunda" opera prima del escritor y cineasta Mario Varela, se estrenó en 2018 , veinticinco años después de la publicación del segundo y último número de la revista de poesía 18 Whiskys. El documental narra el viaje de un poeta desde el sur del país -desde las montañas (o las alturas), su "prueba de existencia"hacia las ciudades de Buenos Aires, Tokio, Rosario y Managua, para reencontrarse con algunos integrantes de la revista: los poetas Fabián Casas, Laura Wittner, Teresa Arijón, Juan Desiderio, Rodolfo Edwards, Ricardo Cerqueiro y Darío Rojo, entre otros. Y, también, con otros protagonistas o testigos de aquella época, como Julia Sarachu, Washington Cucurto y Jorge Aulicino. Podemos hablar de un viaje espacial -el recorrido en sí mismo-, temporal -del presente hacia la juventud-y a la vez de un intento de reconstrucción del yo - de la soledad de las montañas al reencuentro con un grupo de amigas y amigos. Asimismo, todo lo que ya no es resiste en una cinta de video-. Justamente, en este último punto La vida que te agenciaste funciona como un metadocumental y a la vez como la resignificación del propio oficio.

Para el nuevo viaje, Mario Varela parte de las imágenes de otra película, el corto Rally París-Dakar (1993) filmado veinticinco años atrás como un proyecto para la Escuela de Cine de Avellaneda (UDAC). El argumento era una competencia alcohólica por diversos bares de San Telmo. Una serie de imágenes, por momentos difusas, en blanco y negro nos permite reconocer a algunos de los escritores/artistas protagonistas del reencuentro en una noche de alcohol, filosofía y juventud en la ciudad porteña. El cine permite así el retorno imaginario en el tiempo pasado del relato. Allí, entre bebidas blancas, chistes y vandalismo, se mixturan ideas sobre el oficio de escribir poemas, sobre los vínculos entre el alcohol, la amistad y la poesía, y sobre una vida que estaba por delante y que, desde la perspectiva del presente de la narración cinematográfica, se cubre con un velo fantasmal. Aquellos rostros jóvenes se vuelven como esos actores del teatro de la muerte de Tadeusz Kantor que a la vez son los autores de la poesía 
de la época (Monteleone, 2018), que piensan, sonríen, balbucean y hablan frente a la cámara junto a trenes que se acercan peligrosos, mesas que caen, una existencia que ya no es. De algún modo, el corto Rally París-Dakar nos recuerda la escena final de la película Tango Feroz -estrenada también en $1993^{-}$, donde se proyectan, como metaficción, unas tomas previamente registradas por el cineasta del grupo que servirán para eternizar el momento de mayor plenitud de una banda de artistas (el personaje de Tanguito en particular): el amor, el futuro, la creatividad antes de que el mundo los vuelva otra cosa. Esta coincidencia de aquellos años noventa ¿permitiría conjeturar una especie de elegía anticipatoria en el arte de la época? En todo caso, en el contraste entre ambos tiempos que las imágenes construyen con tanta contundencia, en esos rasgos que envejecen literalmente de un cuadro a otro, en los vínculos que ya no son, reside una idea de comunidad. Sin una juventud que se constata perdida -en La vida que te agenciaste el grupo de poetas son su foto del pasado-, sin los fantasmas que habitan en el video, sin confirmar aquello que en el presente ya no existe como tal, no habría comunidad posible. En el medio de todo, como un objeto mítico del que todos hablan pero nadie muestra ni ve hasta la escena final, la revista 18 Whiskys, cuyos dos únicos números son abandonados por el poeta en la orilla del mar Caribe, para ser llevados por la corriente.

Pero, ¿a qué nos referimos con comunidad? Al respecto, el italiano Roberto Esposito (2007) nos propone la idea de deuda como punto de partida. Una comunidad (communitas), señala Espósito, "es el conjunto de personas a las que une, no una propiedad, sino justamente un deber o una deuda. Conjunto de personas unidas no por un más sino por un menos." (2007: 29). Es decir, a partir de una deuda común, de un sacrificio compartido imposible de pagar, de una pérdida. El ejemplo clave que el autor propone es el sacrificio de Cristo: la muerte (y resurrección) que limpia los pecados de los fieles -él "murió por"-. Esa comunidad nace a partir de una muerte y de una deuda impagable. En ese sentido, podemos pensar otro ejemplo más cotidiano: un muerto devenido mártir se vislumbra como una bandera, un motivo, una pérdida que congrega, al menos por un instante, a un grupo de personas a su alrededor, allí donde las diferencias intersubjetivas parecen borrarse-desubjetivarse-en pos de esa ausencia mayor. Pero más que una serie de ejemplos, el abordaje de Esposito posibilita, fundamentalmente, un dispositivo de pensamiento, un cambio de perspectiva para pensar el mundo: la búsqueda de la falta para indagar las distintas formas que adquiere la comunidad.

En este punto, las voces que reconstruyen el pasado en La vida que te agenciaste enuncian a partir de una juventud perdida. Si la enemistad y las distancias en el presente hacen que ya no haya nada en común, los fantasmas que habitan en el Rally ParísDakar funcionan como la pérdida compartida que hace que la comunidad y el pasado sean posibles. Varela, entonces, viaja al pasado para señalar una pérdida y, sacrificada la juventud, recuperar un pasado común con la premisa de refundar el mito grupal. Del mismo modo, en la escena final, después de no ser recibido por Daniel Durand -el único entrevistado que le queda pendiente y, por lo tanto, conservará en el presente constante del filme una juventud detenida, la única imagen que persiste del joven que fue- pondrá en escena por primera vez las dos ediciones de la revista 18 Whiskys, como una ofrenda al mar. A la vez, en una escena del comienzo del documental, Varela y Fabián Casas atestiguan que una librera niega tres veces a la revista, como si se tratara de la negación de Pedro a Cristo; la última escena en la playa potencia, entonces, la idea de mito: la "mítica" revista 18 Whiskys, como dirá Matías Moscardi en La máquina de hacer libritos (2015: 56), aparece como un objeto único, como el resto mágico de aquellos poemas iniciales. Comunidad, poema y origen y el inolvidable olvido detrás del sacrificio. Las revistas que propiciaron el viaje deben desaparecer, fundirse con el mar, ese espacio de origen total. Dejarán un vacío que volverá una y otra vez para 
que las imágenes del pasado, que también podemos pensar como el retrato de una generación, vuelvan a vivir.

4. Como anticipamos, hay otros textos para pensar los vínculos entre comunidad y generación referidos a la poesía del período. Por un lado, La poesía en estado de pregunta (2014) del poeta rosarino Osvaldo Aguirre. Por otro, Hierba sobre el mundo castigado (2017) del llamado "Colectivo poético involuntario". El primero reúne una serie de entrevistas realizadas por Aguirre a algunos de los llamados poetas de los 90, casi todos presentes (o nombrados) en La vida que te agenciaste e integrantes de la 18 Whiskys: José Villa, Fabián Casas, Laura Wittner, Sergio Raimondi y Eduardo Ainbinder (quien no fue parte del staff pero sí publicó una serie de poemas), entre otros. La primera y más extensa entrevista del volumen es la realizada a Daniel García Helder, uno de los referentes -desde su lugar en el Diario de Poesía y como tallerista- de la generación. Al considerar el conjunto, si algo expresan las entrevistas es la ausencia de un proyecto programático o una estética común. Las revistas que ya no existen -y justamente a partir de su inexistencia- ocupan ese lugar de cohesión. Se trata de una generación cuyos puntos de conexión en principio parecen ubicarse en un pasado que resuena efímero. Por su parte, Hierba sobre el mundo castigado es un largo poema experimental construido (compilado, hilvanado, compuesto) por las poetas María Mascheroni y Teresa Arijón, esta última también integrante de la revista 18 Whiskys y protagonista del documental de Mario Varela. El poema o texto colectivo se divide en trece partes y está compuesto por fragmentos de poemas y, en ciertos casos, poemas completos, ensamblados con un método de collage, estrofa por estrofa, a partir de textos publicados por cincuenta y seis poetas argentinos que nacieron entre 1955 y 1965, como Leonor García Hernando, Horacio Fiebelkorn, Martín Prieto, Osvaldo Bossi, Darío Rojo, Macky Corbalán, entre muchos otros. Un fundamento posible detrás de la composición es la reconstrucción de la voz de una época, una atmósfera o un estado de la lengua. Ese conjunto también abre preguntas acerca de la naturaleza del yo del poema y del contraste temporal en el curso de los años. En pleno auge de las redes sociales y los ciclos de lectura, del yo y la extimidad exacerbada, ${ }^{2}$ en Hierba sobre el mundo castigado se privilegia la supresión de la voz autoral en pos de una voz colectiva. Una generación habla aquí como si de las piedras de un río se tratara, una generación que ya es estudiada con fruición. A su vez se presenta un nuevo modo de antologar frente a trabajos históricos como Poesía en la fisura (1995) o Monstruos (2001), compilados por Daniel Freidemberg y Arturo Carrera, respectivamente. Se trata, una vez más, de conformar un vínculo comunitario en el cual el yo individual se borra, para integrar un conjunto discursivo a partir de una voz pluralizada, colectiva, con el fin de señalar, decir, conservar, nombrar un pasado y una "historia perdida". En la presentación del libro, realizada por la poeta María del Carmen Colombo, que considera este volumen como una experiencia (poética) generacional, se lee una observación de Andrés Avellaneda sobre ese aspecto: "Al borrar provisoriamente la autoría, un 'texto colectivo' recoge la hipótesis del fragmento como generador de historia perdida, como hilo de Ariadna para encontrarla" (Colombo, 2017).

¿Podemos, entonces, reflexionar sobre los vínculos entre comunidad y generación? Por ejemplo, ¿puede pensarse una generación desde la idea de sacrificio? En este caso, las voces del coro son las de aquellas y aquellos que fueron niños o jóvenes durante la dictadura y compartieron la atmósfera de la violencia y el terror como primaria educación sentimental. Se trata de un desplazamiento desde la idea de comunidad a la de generación, pero con una misma premisa llevada al extremo. No hay una estética común. Lo que subyace es una pérdida: los muertos de los bombardeos de

2 La noción lacaniana de extimidad fue utilizada por Tamara Kamenszain en Una intimidad inofensiva. Los que escriben con lo que hay (2016) para analizar una serie de poetas afines con la generación del 9o, como Alejandro Rubio, Fernanda Laguna o Roberta lannamico. 
Plaza de Mayo y de la Masacre de Ezeiza; los desaparecidos y asesinados durante la dictadura militar; las víctimas de la pobreza y la exclusión. Sobre esa ausencia, con ese telón de fondo de horror, se construye una subjetividad -que es una desubjetivación colectiva-. Como dijimos, la apuesta de Hierba sobre el mundo castigado es justamente el borramiento de los nombres y la realización de la comunidad en sentido pleno. Una voz mixturada que crece sobre el sacrificio común que una y otra vez vuelve como trauma, como inolvidable olvido que trastocará el ritmo. A través del poema es posible volver a encontrarse con las sombras de los muertos. ${ }^{3}$

Bajo esta premisa, puede trazarse en estos poemas un recorrido que comienza en una ciudad en ruinas, y acaba en un refugio poético, en la reivindicación de la belleza como un don generacional: los desaparecidos y los muertos, por un lado, la belleza del mundo para sobre-vivirlos de ese mismo lado pero como representación. La hierba que crece sobre esas ruinas redime como un lenguaje: el lenguaje que es ausencia de la cosa. Entonces, es a través de la imagen que estas voces logran ponerse de pie, arroparse como fantasmas para indagar en el pasado. Voces que oscilan entre la interpretación, la búsqueda de las correspondencias -esa óptica simbolista mediante la cual Helder y Oscar Taborda discutieron alguna vez el sentido de los animales muertos-y la poesía como evasión, ominosidad o humor sobre la derrota: un caballo espectral que deja su espuma en los alambres y se esconde en una catedral; un choclito que crece para que los andantes lo miren; la revolución que ha "kaputiado" para volverse "revoluta", caricatura de sí: "hemos nacido a tiempo/ para dar a entender" (Colectivo poético involuntario, 2017: 50).

Asimismo, la idea de una generación también puede remitir a un estilo o a una estética determinados. Señala Octavio Paz en El arco y la lira: "El estilo es el punto de partida de todo intento creador; y por eso mismo, todo artista aspira a trascender ese estilo comunal o histórico. Cuando un poeta adquiere un estilo, una manera, deja de ser poeta y se convierte en constructor de artefactos literarios (...). El poeta utiliza, adapta o imita el fondo común de su época -esto es, el estilo de su tiempo- pero transmuta todos esos materiales y realiza una obra única" (1956: 17). Si a cada época le corresponde un estilo que abarca todas sus expresiones artísticas, el poeta deberá trazar allí su diferencia para volverse único, incluso en su derrota o su duelo: su voz como una flor marchitándose en el medio del campo. En el caso de Hierba sobre el mundo castigado el camino funciona de modo inverso: la búsqueda reside en darle forma a un estilo de época, pero no a partir de lo que las voces tienen en común, sino a partir de la diferencia de registros, metros, tonos y lenguajes: una mosaico que combina colores anómalos o, como afirman las compiladoras, una serie de ritmos diversos: "elegimos textos, grandes minucias, versos potentes, basándonos en una vibración (...) son unidades de sentido, movimientos rítmicos" (Colectivo poético involuntario, 2017: 13). Un estado de la lengua a partir de sus variaciones, del flujo que le da forma a "la narración que no termina/ sin maestros en esta historia de hijos cansados" (2017: 36). ¿Qué voz toma forma desde ese agotamiento?

Tanto La poesía en estado de pregunta como Hierba sobre el mundo castigado comparten una obsesión con La vida que te agenciaste. Al afán de recuperar un pasado en distintos términos se le suma la voluntad que una generación, con sus bifurcaciones, tiene de narrarse a sí misma, de repensarse en tanto comunidad desde la disgregación. ${ }^{4} \mathrm{La}$

3 Sobre la cuestión del trauma en la literatura y el arte latinoamericanos, ver el volumen colectivo, dirigido por Spiller, Mahlke y Reinstädler, Trauma y memoria cultural (2020).

4 Fabián Casas, en sus poemas, ensayos y relatos, potencia al extremo esta búsqueda de narrar la historia de la comunidad. En su caso, lo hace a partir de anécdotas o de versiones ficcionales de los poetas de los 9o. Por ejemplo, los poetas que en Ocio (200o) se reúnen a hablar de literatura en el Bar Astral son los poetas que integraban la hoja La Mineta, con Rodolfo Lamadrid (Rodolfo Edwards) a la cabeza. 
identificación de los fantasmas que sostienen cada foto es el eje de la búsqueda: Varela, Arijón y Aguirre. Los protagonistas coinciden en una búsqueda de la ausencia común.

5. El número 7 de La Trompa de Falopo incluye la transcripción de la entrevista que Mario Varela le realizara a Ricardo Cerqueiro, incluida en La vida que te agenciaste, entrevista que evoca una de las imágenes más contundentes del Rally Paris-Dakar: Cerqueiro hablando sobre la poesía, la amistad y el futuro mientras un tren se acerca a sus espaldas. Su voz, que prefigura un sacrificio que no ocurrirá hasta veinticinco años después de su testimonio. Como si estuviéramos frente a la escritura de un poema biográfico. Pero además de funcionar como un homenaje, el último número de La Trompa de Falopo insiste en la idea de comunidad. Si en La vida que te agenciaste, tanto con la ofrenda de las revistas al mar como con la evocación de los fantasmas en el documental enmarcado, se atestiguaba una ausencia que a partir de ahora viviría como un mito en la memoria, la muerte misma del poeta Cerqueiro completa la idea de sacrificio. "El primer muerto" que hace posible que esa comunidad tenga lugar: que todos se vuelvan a sentar alrededor del vacío para cantar por el que ya no está, incluyendo en la evocación a quienes no lo habían conocido. En la primera página, con la presentación del número 7, se lee:

Estamos aquí reunidos, después de debutar en la pantalla grande, para jugar otra vez, aunque ahora estamos tan tristes que no nos sale jugar mucho. Esta es una edición homenaje para el más querido, el tipo que siempre tenía una sonrisa para los amigos, al que la parca lo madrugó bien temprano como dice un tango. Es la edición que nunca hubiéramos pensado que íbamos a hacer. Pero, como siempre, y por toda la eternidad infinita, esta edición y las demás, no son aptas para caretas. (La Trompa de Falopo, 2020: 3)

Como hemos señalado, una particularidad de este número, más allá de un rotundo cambio de estética respecto de los números anteriores (que no será abordado en este trabajo), es su formato digital. Otra pérdida se presupone: la del carácter material de la publicación, su forma de circulación constitutiva. Sin embargo, esa pérdida es la condición para entrar en el diálogo del presente. El pasado se clausura para que un nuevo impulso sea posible. Mario Varela termina su viaje en la publicación de la revista. Los fantasmas hacen pie para que haya, a la vez, comunidad y poema.

Tanto en las entrevistas de La poesía en estado de pregunta, como en Hierba sobre el mundo castigado, se figura una idea de generación, que también compone una idea de comunidad. Mapa de nombres repetidos que se amplia y profundiza a partir de la ausencia. Esa misma ausencia se transfigura como pérdida en La vida que te agenciaste y en la última edición de La Trompa de Falopo. La juventud en tanto pérdida debe volverse fantasma primero, y muerto después, para que vuelva a existir una reunión en el presente. Del mito narrado por los otros a la posibilidad de contar una historia que no es solitaria y propia sino comunitaria: la historia de todos aquellos que ya no son ni están. 


\section{Q Bibliografía}

Agamben, G. (2015 [1985]). Idea de la prosa. Buenos Aires: Adriana Hidalgo.

"Aguirre, O. (2014). La poesía en estado de pregunta. Buenos Aires: Gog \& Magog.

»Bachelard, G. (2015 [1961]). La llama de una vela. Buenos Aires: El cuenco del plata.

» Barthes, R. (2003 [1976-1977]). Cómo vivir juntos. Buenos Aires: Siglo XXI.

»Colectivo poético involuntario (2017). Hierba sobre el mundo castigado. Composición realizada por Teresa Arijón y María Mascheroni. Buenos Aires: Hilos.

»Colombo, M. del C. (2017). Texto de presentación de Hierba sobre el mundo castigado. Blog del amasijo. Disponible en: http://blogdelamasijo.blogspot. com/2017/o7/hierba-sobre-le-mundo-castigado.html

»Esposito, R. (2007 [1999]). Communitas. Buenos Aires: Amorrortu.

»Kamenszain, T. (2016). Una intimidad inofensiva. Buenos Aires: Eterna Cadencia.

"La Trompa de Falopo, 7. (2020). Buenos Aires, octubre. Disponible en: http:// lasraras.com.ar/la-trompa-de-falopo/

»Monteleone, J. (2016). El poema como teatro de la muerte. En El fantasma de un nombre. Rosario: Nube negra.

»Moscardi, M. (2016). La máquina de hacer libritos. Mar del Plata: Puente aéreo.

» Paz, O. (2003 [1955]). El arco y la lira. México D.F.: Fondo de Cultura Económica

»Rimbaud, A. (2007 [1871]). Obras de Arthur Rimbaud. Selección, estudio, versión y notas de Alfredo Terzaga. Córdoba: Ediciones del Copista.

» Spiller, R., Mahlke, K. y Reinstädler, J. (2020). Trauma y memoria cultural. Berlín: De Gruyter.

»Varela, M. (2018). La vida que te agenciaste. Coproducción Argentina-España: AtolladeroCine, En Camino Producciones, Intropiamedia. Disponible en: http://lasraras.com.ar/films/la-vida-que-te-agenciaste/ 